\title{
Die Darstellung der Schattenseiten in Johannes Tralows Roman: „Mohammed“
}

Dr. Yasser Atef Abdullah Muhammad $^{(*)}$

\section{Einleitung}

Niemand kann die Persönlichkeit des Propheten Mohammed $^{1}$ in all ihren Aspekten wahrnehmen. Daher haben sich viele Schriftsteller und Dichter darum bemüht, einige Bilder seiner Persönlichkeit in verschiedenen Formen darzustellen. Einige sind sich dazu verpflichtet, den Propheten nach den beglaubigten Sira-Büchern des Islams darzulegen. Andere haben nicht nur erdichtet, als sie die Eigenschaften des Propheten beschrieben, sondern auch sein Bild verzerrt.

Einige westliche Autoren waren meist gegen den Islam und seinen Propheten wie Johannes Damascenus, Voltaire und sein Roman „Candide“. Diese Autoren bezeichneten den Propheten als einen Boten des Teufels, als Lügner, Zauberer, Kameltreiber und Mörder.

Als muslimischer Forscher und Dozent an der Deutschabteilung der philosophischen Fakultät der Sohag Universität und als Germanist habe ich die Absicht, für meine Untersuchung das folgende Thema auszuwählen: die Darstellung der Schattenseiten in Johannes Tralows Roman: „Mohammed“. Dieser Roman als literarisches Werk ist ein fiktiver Roman, jedoch ist er auch teilweise auf historische Tatsachen beruhend.

(*) Dozent an der Philosophischen Fakultät der Sohag Universität.

1 Im Folgenden wird auf die jeweilige Nennung des Friedenswunsches für den Propheten verzichtet (der muslimische Leser wird dieses sicherlich eigenständig mit seinen Gedanken ergänzen), um den Text leichter lesbar zu machen. 


\subsection{Gegenstand der Untersuchung}

Der Prophet Mohammed ist die größte weltgeschichtliche Gestalt. Durch seine Biographie lassen viele Dichter und Schriftsteller ihre literarischen Werke inspirieren, deren Mittelpunkt das Menschsein des Menschen gegenüber Gesellschaft und außermenschlicher Welt steht.

Der Mohammed-Stoff hat europäische Autoren von Voltaire bis zur Gegenwart zur Darstellung der Gestalt Mohammeds gereizt. Deshalb haben sie das Wirken Mohammeds in der islamischen Geschichte aufgeworfen. Sie haben ihn für den Erlöser der Welt gehalten, weil er die sozialen und politischen Probleme in angemessener Weise lösen könnte.

Das Leben und die Leistungen des Propheten überschwemmen den Büchermarkt im arabischen-islamischen Kulturraum. Im westlichen Kulturraum haben auch viele Autoren versucht, das Leben des Propheten in verschiedenen literarischen Formen darzustellen. Deshalb habe ich dieses Thema als Gegenstand meiner Untersuchung ausgewählt. Da dieses Thema sehr wichtig für uns als Araber und Muslime ist, denn es ist uns von Interesse $\mathrm{zu}$ wissen, aus welcher Perspektive die westlichen Autoren die höchste Persönlichkeit des Propheten sehen.

Diese Arbeit nimmt sich zum Ziel, die Schattenseiten in Johannes Tralows Roman „Mohammed“ darzustellen und zu zeigen, inwieweit der Prophet Mohammed einen festen Platz in der Weltliteratur einnimmt.

\subsection{Bedeutung und Fragestellung der Untersuchung}

Der Roman: „Mohammed“ wird als das wichtigste unter den Werken von Tralow betrachtet, der seine Gedanke und Erfahrungen über den Islam sammelt. 
Durch diesen Roman war Tralows Ziel, seinen Lesern geschichtliche Urteilsfähigkeit zu vermitteln, zugleich sollte jeder seiner historischen Romane ein Stück Gegenwartsliteratur sein. Tralow hat sich von Anfang an mit historisch weit zurückliegenden Themen beschäftigt. Das Geheimnis seines Erfolgs liegt vor allem darin, dass er für seine europäischen Leser unbekannte Welten öffnet.

Entsprechend den Quellen, die er studiert hat, glaubte er, ein objektives Bild zu vermitteln. Er sah seinen Roman in einem Interview als einen Beitrag zur Vertiefung der Freundschaft mit den arabischen Völkern an. ${ }^{1}$ Aber seine Behauptungen, die im Roman erwähnt wurden, widerlegten, was er erklärte.

\subsection{Ziel und Fragestellungen der Untersuchung}

Die Arbeit will folgende Fragen beantworten:

- Was ist die literarische Bedeutung von Johannes Tralow?

- Warum hat Tralow die höchste islamische Persönlichkeit für sein literarisches Werk ausgewählt?

- Wieweit ist es ihm gelungen, das Bild des Propheten nach den anerkannten islamischen Quellen darzustellen?

- Welche Behauptungen gibt es in Johannes Tralows Roman „Mohammed“?

\subsection{Hypothesen der Untersuchung}

Im Rahmen meiner Arbeit interessiere ich mich vor allem dafür, einige Schattenseiten im Roman hervorzuheben.

Obwohl Tralow ein objektives Bild über Mohammed und dessen Leben ohne Andichtung oder Verfälschung geben

1 Anmerkungen zu einer Biographie, Johannes Tralow in die DDR übersiedelt, In: Deutsche Fragen. Informationen und Berichte, Berlin, S. 171f. 
wollte, jedoch verpflichtet er sich nicht dazu, und das kann durch historische Unrichtigkeiten bewiesen werden, die im Roman erwähnt wurden und in denen Tralow legendären und israelitischen Überlieferungen gebraucht: ${ }^{1}$

- Die Beschreibung des Propheten als Götzendiener in der Zeit vor der Offenbarung.

- Die Verzweiflung des Propheten nach dem Tode seines Sohnes.

- Das Empfingen der Offenbarung nach dem Sterben des Sohnes und das Bekehren von Waraka zum Islam.

- Mohammeds Heirat mit Chadidscha durch List und Betrug.

- Die Beschreibung des Propheten als Weintrinker.

- Die feindliche Beziehung zwischen Fatima und Aischa.

- Mohammed nutzt seine Offenbarung zur Realisierung persönlicher Wünsche und Absichten aus.

- Die Eroberung Mekkas zur Stabilisierung der Macht Mohammeds, u.a.

\subsection{Motive der Untersuchung}

In meiner Arbeit beschäftige ich mich mit Johannes Tralows Roman: „Mohammed“. Da dieses Thema mir von großer Bedeutung ist, habe ich es für wichtig gehalten, dieses Thema zu erforschen. Es ist mir ein Anliegen, einige Schattenseiten in Johannes Tralows Roman: „Mohammed“ hervorzuheben.

Nachdem Tralow seinen Roman ,Kepler und der Kaiser' beendet hatte, begann er sich in die Geschichte des osmanischen Reiches durch sein Werk "Die Osmanische Tetralogie" zu vertiefen. Infolgedessen entstand bei ihm eine Triebkraft zu wissen, aus welcher Quelle sich das osmanische

1 Die folgenden Behauptungen und die legendären Überlieferungen, die Tralow in seinem Roman erwähnt hat, werden im Folgenden ausführlich dargelegt und beantwortet. 
Reich seine Stärke und seine strengenden Gesetze abgeleitet hat, bis er die größte Macht in der Welt wurde. Dies gab ihm den Anstoß dazu, sich mit der Geschichte des Islam, die sich das Leben und die Biografie des Propheten herausstellen soll, zu beschäftigen.

Zugleich hatte Tralow viele Gespräche mit den Lesern seiner „Osmanischen Tetralogie“ geführt, die den Islam nicht gut wahrnehmen können, dann erschien es ihm notwendig zu sein, seiner Leserschaft den Islam in einer konkreten Form näherzubringen. Das war der ihm bestimmende Beginn zum „Mohammed“.

Tralows Zweck war es, den Lesern das Leben des Propheten in einer ganz neuen Form interessanter und beliebter darzustellen und den Islam in einer konkreten Form näherzubringen. ${ }^{1}$ Tralow erläutert dies sagend:

,$[E s]$ ist für mich die Notwendigkeit, meiner Leserschaft den Islam in einer konkreten Form näherzubringen. [...] Denn in der Lebensgeschichte des Propheten liegt zugleich der Islam als eine selbständige Religion beschlossen. Nachdem ich mich mit der Person und dem Leben Mohammeds beschäftigt hatte, schrieb ich nur kurz vor meinem 80. Geburtstag den ersten Satz, nach vier Jahren schrieb ich den letzten. "

Nach Meinung von Abu Hattab gilt Johannes Tralows „Mohammed“ als ein wichtiges Beispiel für die Mischung aus Wohlwollen und Unverstand dem Islam gegenüber. Diese Mischung ist für eine Periode europäischer Islamdarstellungen

1 Demzufolge sollte der Roman „Mohammed“ im Interesse der Leserschaft vor dem Druck der "Osmanischen Tetralogie" erscheinen. Nach seiner Veröffentlichung fand der Roman großes Interesse und erreicht die Auflagenhöhe im Jahre 196840000 Exemplare.

2 Tralow: Leben und Werk, die Deutsche Staatsbibliothek Verlag, Berlin, 1968, S. 31. 
typisch. Sie hat mit dem Zeitalter der Aufklärung begonnen und etwa mit diesem Werk zu Ende gegangen. ${ }^{1}$ Durch diesen Roman ist Tralows Ziel, eine Persönlichkeit wie Mohammed hervorzuheben, die den Kapitalismus durch den Sozialismus ersetzen kann.

\section{Zur Darstellung einiger Schattenseiten in Johannes} Tralows Roman: „Mohammed“6

Tralows Roman „Mohammed“ behandelt das Leben und die Gestalt des Propheten Mohammed von der ersten Offenbarung bis zu dem Tod in Medina.

Tralow beginnt seinen Roman mit der Beschreibung des Lebens in Mekka als ein friedliches und zufriedenes Leben für die Bürger. Tralow beschreibt gleichzeitig das Nachsinnen Mohammeds nach dem Tod seines Sohnes, was ihn veranlasst, Gott zu suchen. Er zieht sich in die nach Mekka nahe gelegene Höhle Hira zurück. Dort meditiert er über alle Religionen, welche er auf seinen Handelsreisen kennengelernt hatte, sowie die Religion seiner Heimat Mekka, und so laufen die Ereignisse, bis zum Tod Mohammeds in Medina kurz nach seiner letzten Wallfahrt nach Mekka.

\section{Beschreibung des Propheten als Götzendiener in der Zeit vor der Offenbarung}

Tralow stellt gleich zu Beginn des Romans den Propheten in der Zeit vor der Offenbarung als Götzendiener dar, gleich den anderen Mekkanern:

„Als Wahnsinn jedoch wollte dem Mann sein Leben vergangener Tage erscheinen, als er noch wie alle anderen zum Götzen Hubal in die Kaaba gelaufen war

\footnotetext{
${ }^{1}$ Abu-Hattab, Muhammad: Johannes Tralows Roman: „,Mohammed“. In: Wissenschaftliche Zeitschrift der Fremdsprachenfakultät der Al-AzharUniversität, 12/1982, S. 5.
} 
und zu den Altären der Götzinnen al-Lat, al-Uzza und [...] Manat, um dort ein geringes zu opfern. "“l

Die glaubwürdigen Sira-Bücher jedoch, in denen alle Überlieferungen zur Lebensgeschichte des Propheten gesammelt sind, sind sich darüber einig, dass der Prophet auch in seiner Jugend nicht $\mathrm{zu}$ den Altären der Götzen gelaufen war². Es gab keine Überlieferung, dass er sich vor einem Götzen unterwarf. Er nahm auch nicht daran teil, mit Altersgenossen $\mathrm{zu}$ spielen und $\mathrm{zu}$ spaßen. Von jeher galt er unter seinen Altersgenossen als Vorbild, weshalb er unter den Mekkanern als „Al-Șadiq“ und „Al-Amịn“ bekannt war, das heißt ,der Aufrichtige“ und ,der Treue ${ }^{63}$

\section{Die Verzweifelung des Propheten nach dem Tode seines Sohnes.}

Mohammed wird anfangs von Tralow als fanatischer Götzendiener dargestellt, dessen Fanatismus so weit führt, dass er seinem Sohn sogar einen Götzennamen gibt. Tralow beruft sich bei der Schilderung Mohammeds als Götzendiener auf eine Überlieferung voller Widersprüche. Diesen Namen hat Mohammed seinem Sohn gegeben, als er noch auf dem heidnischen Standpunkt seiner Landsleute stand. ${ }^{4}$

Tralow, Johannes: Mohammed. Historischer Roman, Berlin: Verl. D.

Nation 1967, S. 9.

${ }^{2}$ Ibn Hischam, Abi Muhammad 'Abd Al-Malik: As sira Anabawiya (Die

Sira des Propheten), Mu'asaset Al-Ma'aref lel Tebā'a wa Anasr,

Beirut, Lebanon,1428d.H/2007, Bd. 1, S. 190.

ابن هشام، أبي عبدالملك: السيرة النبوية، الطبعة الأولى، موسوعة المعارف للطباعة والنشر،

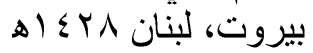

3 Al-Hudairy, Muhammad 'Afifi: Nour Al-Yakeen fi Sirat Sayed AlMursalleen(Das Licht der Gewissheit in Biografie von Herrn der Gesandten), Dar Al-Ma'aref, 2004, S. 7.

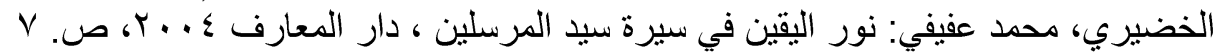

${ }^{4}$ Sprenger, A.: Das Leben Mohammeds, Leipzig 1930, S. 93. 
Aus der unsicheren Überlieferung des Namens versucht nun Tralow, die innere Entwicklung Mohammeds und dessen Weg zur prophetischen Sendung abzuleiten.

Mit dem Tod von Mohammeds Sohn, der diesen Götzennamen trug, beginnt die eigentliche Entwicklung seines Helden. Der Tod seines Lieblings machte aus ihm einen skeptischen und wissensdurstigen Mann. Es ging ihm dabei nicht allein um das Wissen, sondern vielmehr darum, der Qual seines Sohnes ein Ende zu setzen, die dieser, wie Mohammed glaubte, durch den Götzennamen ertragen musste. Er suchte nach einem Ausweg, und er ging zu den ausländischen Gästen, weil sie ihm von ihrem Propheten Jesus erzählen konnten. Mohammed aber sagte dieser Religion (Christentum) nicht zu. Der Allmächtige brauchte den verschlungenen Weg des Irdischen nicht; er brauchte keine Söhne und Töchter, die immer nur Götzen und Göttinnen hätten sein können. ${ }^{1}$

Mohammed besuchte auch die Juden mit großem Interesse. Sie glaubten, Gott wäre nur ihnen eigen, sie waren das von Gott selbst auserwählte Volk,

„als wenn der Einzige sich mit den Juden begnügt hätte oder gar ihr Eigentum hätte sein wollen![... $]^{2}$ “.

Bei den ausländischen Gästen, ob Juden oder Christen, hatte Mohammed aber das Wissen nicht um das Gewaltige, worauf es ihm eigentlich ankam, gefunden.

Mohammed musste seines unschuldigen Knaben gedenken, dessen Götzenname allein die Hölle öffnete und das Paradies verschloss, denn der Vater Mohammed hätte ihm in seiner Unwissenheit und Verblendung diesen Namen gegeben.

Tralow: Mohammed, a.a.O., S. 8.

2 Ebenda, S. 8. 
Deshalb war es seine Absicht gewesen, die Höllenqualen sein Sohn zu vermindern, indem er sie auf sich nahm.

Auf der Suche nach der Spur Gottes ging er in die Einsamkeit, die er auf dem Berg Hira fand. Dort war Mohammed verzweifelt und ,,immer verstörter geworden “ und er

„geißelte seinen Rücken wild und wütend, bis ihm das Blut herunterrann "l

Schließlich wurde er bewusstlos. Erst nach zwei Tagen, als er seltsame Laute vernahm, Ließ er davon ab. Er schrie mit aller Kraft zum Himmel um das Zeichen, bis endlich ein Ruf zu ihm kam. Dies war die erste Offenbarung.

Als Mohammed den Engel zum ersten Mal sah, wollte er sich verbergen, bis er den Anblick der Irdischen wieder ertragen kann. In diesem Augenblick hoffte Mohammed, wie der Roman erachtet, den Tod.

„Wenn er eine Wahl gehabt hätte, hätte er den Tod im Abgrund gewählt. Doch das wäre Tod und kein Heil gewesen. "2

Womit Tralow darstellen will, in welchem Geisteszustand Mohammed, seiner Vorstellung nach, die erste Offenbarung empfangen hat.

Auf diese Weise schildert der Autor den Kampf Mohammeds um das Zeichen Gottes und führt die ganze Entwicklung seines Helden auf den Götzennamen des Sohnes zurück. Er versucht damit, eine annehmbare Begründung dafür zu geben, wie Mohammed auf den Weg zur Offenbarung gelangte.

Tralow: Mohammed, a.a.O., S. 10.

2 Ebenda, S. 13. 
Dafür hat Tralow aber aus eigener Vorstellung seinem Helden Neues zugedichtet. Die Offenbarung Mohammeds war also ein Ergebnis des langen Ringens um die Erlösung des Sohnes:

„Unser Söhnchen [...] Er [Gott] hat mir verziehen. Wir können dem Sohn einen anderen Namen geben. Ich möchte ihn Abd Chadidscha nennen.“ „Der Tod entscheidet nichts. " ${ }^{1}$

Mohammed verkündet dies seiner Gattin Chadidscha. Und darauf kommt es Mohammed an, wie Tralow zu verstehen gibt.

Das steht zum Islam im Widerspruch, weil sein im Roman gemeinter Sohn erst starb, nachdem Mohammed bereits zum Propheten erwählt war. Der Prophet hatte zwei Söhne von seiner Frau Chadidscha: der erste war Al-Qasim, und der zweite hie $\beta$,Abdullah“, der zwei Beinamen Al-Ṭāhir (der Reine) und Al-Ṭayeb (der Gute) trug. Beide Söhne starben nach der Offenbarung und als sie Kleinkinder waren. ${ }^{2}$ Darum hat Quraisch den Propheten vorgeworfen und als den schwanzlosen $^{3}$ Mann bezeichnet, wie in Sūra 108 al-Kautar, Vers 3 lautet:

„Gewiss, derjenige, der dich haßt, - er soll ohne Nachkommenschaft sein. "

1 Tralow: Mohammed, a.a.O., S. 24.

${ }^{2}$ Vgl. Haikal: Hayāt Muhammad (Das Leben Muhammads), a.a.O. S.368. قارن: هيكل، محمد حسين: حياة محمد، الهيئة المصرية العامة للكتاب، دار المعارف، القاهرة،

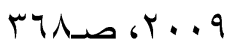

${ }^{3}$ d.h., Er hat kein männliches Kind

4 As-Șāmit, 'Abdullāh, Frank Bubenheim, Nadeem Elyas: Der edle Qur'ān und die Übersetzung seiner Bedeutungen in die deutsche Sprache, a.a.O., Sūra 108, al-Kautar, Vers 3.

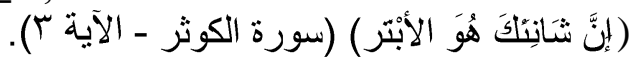


Herabsendung der Offenbarung und das Bekehren von Waraka zum Islam

Die Gestalt von Waraka wurde mit großer Sympathie geschildert. In allem, was Waraka sagte, ,w war er von äußerster Genauigkeit"." Tralow sieht in Waraka eine Gestalt, durch deren Meinungen und Äußerungen er zusätzliche Gedanken und Kommentare einflechten kann, wenn ihm die Handlung und Entwicklung des Helden oder der Situation zu einer direkten Stellungnahme keine Gelegenheit bieten. Waraka hielt von Wundern nichts und mit seinem Verstand suchte er $\mathrm{zu}$ durchdringen, was an nebelhaftem Brauchtum um ihn herum waltet. Damit gewinnt der Autor eine Distanz und eine beobachtende Haltung zu den Ereignissen.

Die aufklärerische Haltung Tralows kommt auch darin zum Ausdruck, dass er Waraka einen skeptischen, aufklärerischen Intellektuellen beigibt, der Mohammeds Sendung kritisch kommentiert. Waraka ist einer der ersten, treuesten, aber auch klügsten Mitstreiter des Propheten, der in zahlreichen Entscheidungssituationen den Ausschlag gibt.

An einigen Stellen tritt Waraka im Roman in den Hintergrund. Damit wird gezeigt, dass er an der Weiterentwicklung des Islam keinen Anteil hatte, als er zu einer politischen Erscheinung wurde. Der Autor lässt Waraka Sätze von ausschlaggebender Bedeutung sagen. ${ }^{2} \mathrm{Er}$, der ein hohes $\mathrm{Maß}$ an Gewandtheit im Gespräch besaß, fragte Othman('Osmān), den Schwiegersohn Mohammeds, ob Mohammed ihm zu einem bestimmten Problem nicht antworten könne. Othman erwiderte:

„Das hat er nicht nötig. Wenn Mohammed spricht, hat Allah gesprochen, und den kannst du nicht fragen. “

Tralow: Mohammed, a.a.O., S. 31.

2 Vgl. Ebenda, S. 395f. 
Waraka sagte darauf:

"Natürlich nicht. Mit einer Offenbarung ist jeder
erledigt. "Il

Hinzu behauptete Tralow, dass Waraka, während des mit Othman führenden Dialogs, zum Islam bekehrte,

„Damit war für die Gelegenheit gekommen, von Mohammeds Offenbarungen zu berichten und von dem Gebet der Gläubigen, deren ersten einer er, Waraka, war s. $^{2}$

Dagegen hat der gelehrte Waraka laut den Sira-Büchern gar nicht lang genug gelebt, um selber Muslim werden zu können. ${ }^{3}$

\section{Die Hervorhebung Mohammeds als kein Analphabet}

Aus der bisherigen individuellen Entwicklung Mohammeds geht, Tralows Darstellung nach, deutlich hervor, dass die Offenbarung also das Ergebnis des qualvollen Kampfes um die Verminderung der Höllenqual des Sohnes war.

Eine solche Entwicklung, wie sie Mohammed durchlief, konnte kein Analphabet durchmachen. Deshalb und entgegen den meisten arabischen Überlieferungen war Mohammed bei Tralow des Lesens und Schreibens kundig.

Das ist jedoch eine Frage, die sowohl vom Koran (Qur'ān) als auch von der geschichtlichen Überlieferung entscheiden kann.

Tralow: Mohammed, a.a.O., S. 396.

Ebenda, S. 35.

${ }^{3}$ Vgl. Haikal: Hayāt Muhammad (Das Leben Muhammads), a.a.O. S. 122.

هيكل، محمد حسين: حياة محمد، الهيئة المصرية العامة للكتاب، دار المعارف، القاهرة، 9 . . ب، 
Mohammed war sowohl laut Koran als auch laut geschichtlicher Überlieferung ein Analphabet. Sūre 7, Vers 157 und Sūre 29, Vers 48 weisen darauf hin,

„Die dem Gesandten, dem schriftunkundigen Propheten, folgen, den sie bei sich in der Thora und im Evangelium aufgeschrieben finden“. „Und du hast vor dem kein Buch verlesen und es auch nicht mit deiner rechten Hand niedergeschrieben. Sonst würden wahrlich diejenigen zweifeln, die (es) für falsch erklären "'l.

Die ersten Verse, die ihm herabgesandt wurden, kamen gleich mit der Forderung zum Lesen. Seine Antwort war, dass er nicht lesen könne.

„Lies im Namen deines Herrn, Der erschaffen hat, den Menschen erschaffen hat aus einem Anhängsel. Lies, und dein Herr ist der Edelste, Der (das Schreiben) mit dem Schreibrohr gelehrt hat, den Menschen gelehrt hat, was er nicht wusste ${ }^{\omega^{2}}$.

Der Koran wurde auch nicht von ihm persönlich niedergeschrieben, sondern unter seiner Aufsicht und auf seiner Forderung von seinen Anhängern, er hatte zwölf seiner Anhänger diesen Zweck auszuführen ausgewählt. Wenn er schreiben und lesen könnte, dann hätte er selbst die Offenbarung geschrieben.

1 As-Șāmit, 'Abdullāh, Frank Bubenheim, Nadeem Elyas: Der edle Qur'ān und die Übersetzung seiner Bedeutungen in die deutsche Sprache, a.a.O., Sūra 7 al-A'rāf (Die Höhen), Vers 157 und Sūra 29 al'Ankabūt (Die Spinne), Vers 48.

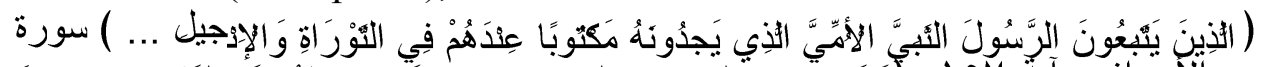

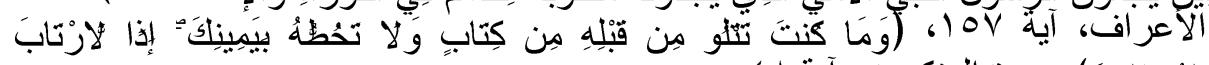

2 Ebenda, Sūra 96 al-'Alaq (Das Anhängsel), Vers 1-5.

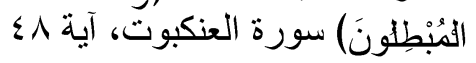

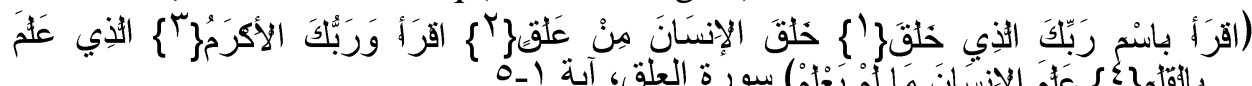


Mohammeds Heirat mit Chadidscha durch List und Betrug und deren Beschreibung als Weintrinker

Mohammeds Streben nach Besitz wird von Tralow in den Mittelpunkt gerückt. Er hat bereits verschiedene und zweifelhafte Mittel zur Besitz angewendet. List und Betrug waren ihm recht, wenn sie ihm sein Ziel näherbrachten. Aus diesem Grunde heiratete er auch Chadidscha.

Tralow zeigt durch die Geschichte der Verehelichung Mohammeds mit Chadidscha, die 15 Jahre älter als er war, seinen Helden noch von einer anderen Seite: Mohammed sei bereit, eine Frau auch mit List und Trug zu erringen. In diesem Zusammenhang berichtet Tralow über die Ehe in Arabien zu Mohammeds Zeit; es gab mindestens drei anerkannte Arten von Eheschließung:

„Als die meistverbreitete Ehe hatte sich die durchgesetzt, bei der Frau und Kinder unter die Herrschaft des Mannes gerieten \{...\} Weniger geachtet war die Ehe auf die Zeit, doch immerhin anerkannt, und schließlich gab es die Ehe, deren Meisterin die Frau war. "'l

Eine derartige Ehe war Chadidschas Ehe mit Mohammed. Über Mohammeds Ehe mit Chadidscha hat Tralow eine Geschichte angedichtet, in der es heißt,

„dass man ihren eigensinnigen Vater Chulaid damals betrunken gemacht habe, damit er die Tochter im Rausch mit Mohammed ibn Abdallah zusammengäbe "²

Auf diese Weise wird offenbar zum Ausdruck gebracht, dass Mohammed schon vor seiner göttlichen Sendung bereit war, jedes Mittel zur Erreichung seines Ziels anzuwenden. Hier war sein Ziel, das Vermögen Chadidschas zu gewinnen, auch wenn Tralow das nicht direkt als Grund erwähnt.

\footnotetext{
${ }^{1}$ Tralow: Mohammed, a.a.O., S. 40.

2 Ebenda,
} 
Aber seine Behauptung ist nicht richtig, denn Chadidscha war erstens sozial unabhängig, als sie die Ehe mit Mohammed einging, und konnte heiraten, ohne Einwilligung ihres Vaters; zweitens war ihr Vater zu diesem Zeitpunkt bereits tot. ${ }^{1}$

Weiter schildert Tralow eine Feier des Elefantenjahres im Haus Mohammeds:

„Es fehlte ja weder an Wein noch an Frauen und Mädchen, die ihm nicht nur einschenken und reichten, sondern auch tranken ${ }^{2}$

Die Quellen über das Leben Mohammeds stimmen zudem darin überein, dass der Prophet nie Wein getrunken hat und dass er auch Gesellschaften mit Schank- und Animiermädchen Zeit seines Lebens ferngeblieben ist. ${ }^{3}$

\section{Mohammed nutzt seine Töchter als Mittel zur Stärkung} seiner schwachen Gemeinde aus

Mohammed hatte nach der Überlieferung von Chadidscha mehrere Kinder. Vier von ihnen waren Mädchen: Zeinab, Ruqaija, Faṭima und Um Kalțum.

Frants Buhl erwähnt diese Tatsache und fügt hinzu, dass über die vier Mädchen volle Übereinstimmung in der Überlieferung herrscht. ${ }^{4}$

Ruqaija und die jüngere Schwester Um Kalthum waren nach der Überlieferung mit den beiden Söhnen des Abu Laḥab, Mohammeds Onkel, verheiratet. Als Mohammed mit seiner

${ }^{1}$ Haikal: Hayāt Muhammad (Das Leben Muhammads), a.a.O., S. 112.

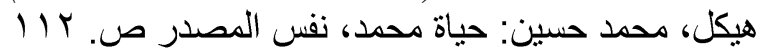

2 Tralow: Mohammed, a.a.O., S. 53.

${ }^{3}$ Haikal: Hayāt Muhammad (Das Leben Muhammads), a.a.O., S. 127. هيكل، محمد حسين: حياة محمد، نفس المصدر ص. Trat

4 Vgl. Buhl: Das Leben Mohammeds, a.a.O., S. 120 und Haikal: Hayāt Muhammad (Das Leben Muhammads), a.a.O. S. 117. 
neuen Religion auftrat und Abu Laḥab versucht hatte, Mohammed vergeblich von seinem Vorhaben abzubringen, befahl er seinen Söhnen, sich von den Töchtern scheiden zu lassen, was sie dann auch taten. Ruqaija war demnach vor ihrer Ehe mit 'Osmān schon einmal verheiratet gewesen, und zwar mit Utba, einem Sohn Abu Lahabs.

Tralow schildert die Geschichte anders, indem Mohammed seine Tochter Ruqaija als Mittel zur Stärkung der noch schwachen Gemeinde dient.

„Als Rukaija ihn [Utba] also den Stall winkte, [...] folgte ihr in der Überzeugung, sie bereits zu haben, während er -wie so viele Mannsbilder in ähnlichen Fällen- an ihrer Angel hakte" "l

'Utbas Liebe zu Ruqaija war so groß, dass er ihr die höchste Morgengabe anbot. 'Utba war jedoch Heide und blieb fest bei seinem Glauben. Utba geriet in Zahlungsschwierigkeiten und konnte nicht die versprochene Summe aufbringen. So hatte sich Chadidscha von ihrem Versprechen -Ruqaija an 'Utba zu geben- mit der Begründung losgesagt, dass Mohammed seine Tochter an keinen Heiden verheiraten würde. Darauf spekulierte 'Utbas Rivale 'Osmān. Dieser war im Gegensatz zu 'Utba sofort bereit, seinen heidnischen Glauben aufzugeben und den Islam anzunehmen.

Mit dieser Begebenheit wird zudem gezeigt, auf welcher Grundlage Mohammed seine junge Gemeinde aufbaute. Er benutzte seine Tochter, um einen wohlhabenden Mann des führenden Stammes 'Omaya als Mitglied sowohl in der Gemeinde als auch in der Familie zu gewinnen. So schildert Tralow 'Osmān, der später zu den größten vier Männern zählte, die Mohammeds Nachfolger wurden.

${ }^{1}$ Tralow: Mohammed, a.a.O., S. 17. 
Durch die Gestalt 'Osmāns versucht Tralow ein Bild der Charaktere der wichtigsten Gläubigen zu geben. 'Osmān ging es um Ruqaija und Mohammed um die Vergrößerung seiner Gemeinde.
„Das ist wohl wahr. Er ist ein Omaijade, seine Mutter eine Rabia, er ist mit allen vornehmen Familien verwandt, [...] hat auf das Volk einen großen Eindruck gemacht "'l

Auf diese Weise zeigt Tralow einen Mitbegründer der islamischen Gemeinde, der zu Mohammeds Religion, nicht aus Überzeugung, übertrat.

\begin{abstract}
„Lass uns annehmen, dass Othmans Verliebtheit größer sei als sein Glaube, so würde das doch heißen, dass Rukaija sein Weg zum Glauben ist, dass Allah sie also gesegnet hat. soll der Glaube den Gläubigen verarmen? Othman hat ein Gutteil seiner Vielfalt bewahrt, er glaubt und liebt, und der Gemeinde der Gläubigen brachte seine Bekehrung Gewinn. "²
\end{abstract}

Dieser nicht überzeugt aufgebaute Glaube drückt sich darin aus, dass 'Osmān als nicht besonders aktives Mitglied in der Entwicklung des Islams dargestellt wird. Er war an den großen Schlachten nicht beteiligt. Durch seine zurückhaltende Gesinnung gegenüber der neuen Religion eignete er sich als guter Unterhändler bei den Mekkanern, da er nicht in offenem Kampf mit ihnen stand.

Tralow hat sich in seiner Beschreibung der Persönlichkeit 'Osmāns auf der Behauptungen der Schiiten gestützt. Aber das ist nicht richtig. Er war an den großen Schlachten nicht beteiligt wie Badr, weil der Prophet ihm befahl, mit seiner kranken Ehefrau zu bleiben und sie zu pflegen.

\footnotetext{
Tralow: Mohammed, a.a.O., S. $78 f$.

2 Ebenda,
} 
Die ungerechte Behandlung Mohammeds gegenüber seinen Töchtern

Mohammed hatte seine Tochter Fatima nicht geliebt, nach Tralows Schilderung wurde sie sogar von Mohammed misshandelt. Im Sterbebett ließ Chadidscha Mohammed zu sich kommen; ihre letzte und einzige Bitte war, von Mohammed das Versprechen zu erhalten, dass er nach ihrem Tod die Tochter Fatima lieben und sie an einen Gläubigen verheiraten soll. Dies lässt Tralow durch Fatima selbst bestätigen,

„O Vater “, überfiel Fatima ihn, „hilf der Mutter, und wenn du kein Wunder tun magst, dann bete - Oh bete! Dir wird Allah deine Bitte gewiss nicht versagen. Wenn die Mutter uns verlässt, dann bin ich ganz allein, dann hat mich niemand mehr lieb... “"

Mohammed antwortete darauf:

„Solange ich lebe, hat auch dein Vater dich lieb, Fatima. "

Unzufrieden nickte die Tochter:

„Jawohl!... Weil Allah es dir befiehlt, darum bist du auch zu mir gut; aber nicht, weil du mich wirklich liebst.... ${ }^{3}$.

Chadidschas letzte und dringlichste Bitte an Mohammed war es, dass er als Prophet seine Tochter Fatima nicht vernachlässigen sollte. So wird Mohammed als ein Mensch dargestellt, der seinen väterlichen Pflichten nicht nachgekommen war, darüber hinaus soll er seine Kinder selbst nicht gerecht behandelt haben.

\footnotetext{
Tralow: Mohammed, a.a.O., S. 138.

2 Ebenda,

${ }^{3}$ Ebenda,
} 


\section{Die feindliche Beziehung zwischen Fatima und Aischa}

Mohammed sollte - nach der Bitte Chadidschas - seine Tochter Fatima mit einem Gläubigen verheiraten. Tralow beschreibt nun im Roman, wie geschickt Mohammed die Bitte seiner Frau erfüllte; Mohammed wollte Aischa, die gleichaltrig mit Fatima war, heiraten. Da die beiden sich aber von Kindheit an hassten, war er gezwungen, Fatima zuvor mit Ali zu verheiraten. Nach einem Streit, den Fatima vom Zaune gebrochen hatte, entwickelte sich folgendes Gespräch: „Fatimas Stiefmutter kann Aischa nicht sein“.

Mit der Verheiratung Alis mit Fatima wurde er seine Tochter, die er nach Tralows Ansicht nicht liebte, los. Und zugleich konnte er Aischa heiraten und hat schließlich damit auch sein Versprechen an Chadidscha erfüllt.

Die von Tralow beschriebene Feindschaft zwischen Fatima und Aischa ist frei erfunden. Er geht so weit zu behaupten:

„Fatima aber hasste Aischa und hatte auch bei Aischa keine Liebe erwecken können. Treibst du dich hier auch schon wieder herum? Du rothaarige Hexe! \{...\} Eine Tochter Iblis' bist du $\{\ldots\}^{\text {"Il }}$

Auch lässt er Fatima erneut Aischa verfluchen:

„Dreimal verflucht und dreimal siebenmal verflucht, rothaariges Gespenst, Tochter des Scheitan! “2

\section{Die Stellung Mohammeds den Dichtern und den Gegnern gegenüber}

Tralow beschreibt die Dichter in Mekka als Urheber und Lenker der öffentlichen Meinung. Ein Stamm, der seine

Tralow: Mohammed, a.a.O., S. 132

${ }^{2}$ Ebenda, S. 184 
Mitglieder im Stich ließ, würde die Spottgedichte auf der nächsten Messe zu hören bekommen;

„Es gab keine geschriebenen Gesetze, aber es gab Gedichte - geliebt und gefürchtet - wie es sich traf. “l

Seit der Machtübernahme der Kureischiten hat es in Mekka keine bewaffneten Auseinandersetzungen mehr gegeben, die es in anderen Städten gab. Tralow begründet die Sonderstellung Mekkas mit der Existenz einer „Mala“, einer Vereinigung angesehener Männer. Ihre Aufgabe besteht darin, Streitigkeiten und Zwistigkeiten beizulegen, geschehenes Unrecht, sei es an einem auswärtigen Gast oder an einem Einheimischen verübt, $\mathrm{zu}$ schlichten.

Tralow hebt damit die Organisation der Stadt Mekka auf eine höhere Stufe, um damit die Notwendigkeit der Existenz eines Propheten zu negieren.

Märchenerzähler waren nach Tralows Schilderung weniger gefährlich als die Dichter. Ihr Ziel war nur, die Leute zu unterhalten, nicht, um die Meinungen der Zuhörer zu werben.

„Märchen wollten nur unterhalten. Ihre Erzähler kämpften durch ihren Vortrag lediglich um die Anerkennung der Kunst des Erzählens und gegen jegliche Langeweile. " ${ }^{2}$

Für Mohammed gab es nur seine Offenbarungen, die er als Botschaft göttlichen Ursprungs auffasste und nicht als Ausstrahlungen seines eigenen Geistes. Die Gläubigen waren genauso von seinen Offenbarungen überzeugt wie er. Aber das Märchen von Nadr ibn Al-Harith erwachte in Mohammed den Hass gegen alle Dichter und Märchenerzähler, da er sich ihnen zu unterlegen fühlte.

Tralow: Mohammed, a.a.O., S. 29

2 Ebenda, S. 88. 
„Mohammed Ibn Abdallah war kein Märchenerzähler. Er würde sich eine solche Behauptung sehr verbeten haben, und mit der gleichen Empfindlichkeit stand er Wahrsagern und Dichtern, vor allem den Dichtern, gegenüber, die er hasste. Er hätte sich überhaupt alles verbeten zu sein, außer was er war, nämlich Mohammed ibn Abdallah, der Haschimit und Allahs Prophet. "'l

Dies ist im Roman der einzige Grund dafür, Mohammed zum Töten Nadr ibn Al-Harith, den Märchenerzähler anzustiften. Hiermit zeigt Tralow die Humorlosigkeit seines Helden; Mohammed fehlte das Verständnis, denn die dichterische Behandlung der Dinge, leicht oder gar ironisch, kann jedenfalls nicht mit der Offenbarung verglichen werden. In der Überlieferung wird Mohammed auch in dieser Situation als gütig und tolerant gezeigt. Durch folgende Begebenheit wird dies $\mathrm{zu}$ belegen versucht: Als die Schwester des ermordeten Märchenerzählers ihren Bruder mit einem rührenden Trauergedicht beweinte und Mohammed dies hörte, sagte er:

„Wenn ich das vorher gehört hätte, hätte ich ihn nicht töten lassen. “2

Gleichzeitig zeigt Tralow mit dieser Schilderung an, dass sein Held außerstande war, seine Gegner mit denselben geistigen Mitteln zu bekämpfen. Mohammed nahm im Koran gegen die Dichter Stellung, indem er sie als Lügner bezeichnete und von denen nur willenlose Menschen begeistert sein können.

„Und die Dichter - es folgen ihnen die Verirrten. Siehst du nicht, dass sie in jedem Tal ziellos

Tralow: Mohammed, a.a.O., S. 88.

2 Iben Hischam: As sira Anabawiya (Die Sira des Propheten), a.a.O., Bd. 2, S. 43. 
umherwandern und dass sie sagen, was sie nicht tun "l

Um den Mord gegen Nadr ibn El-Harith zu rechtfertigen, zeigt die islamische Geschichte die Rolle des Nadr und seine Gefahr für Mohammed und dessen Religion. Die islamische Überlieferung stellt Nadr als Hauptfeind des Propheten dar und wegen dessen Feindschaft muss er getötet werden. Die Gefährlichkeit des Nadr besteht darin, dass er nach jeder Predigt Mohammeds die Versammelten aufhält und versucht, die Worte Mohammeds zu widerlegen. Danach erzählte er ihnen Märchen und fragte die Anwesenden:

„Ist das nicht besser als Mohammeds Predigt, die er Gottes Worte nennt? " ${ }^{2}$

Außerdem hat er gegen Mohammed überall gehetzt und die Stammesführer in Mekka vor seinen Machtansprüchen gewarnt.

Tralow schildert dagegen den später ermordeten Nadr ibn El-Harith als einen harmlosen Märchenerzähler, der auf keine Weise den Tod verdient hatte. Damit will Tralow zeigen, dass Mohammed auch schon vor seiner Auswanderung nach Medina politische Ziele verfolgt habe.

Die Darstellung der Standhaftigkeits-Positionen

Mohammeds als Resignationspositionen

Nach den eigentümlichen Rechtsverhältnissen der arabischen Stämme war der Schutz Mohammeds durch seinen

${ }^{1}$ As-Ṣāmit, 'Abdullāh, Frank Bubenheim, Nadeem Elyas: Der edle

Qur'ān und die Übersetzung seiner Bedeutungen in die deutsche Sprache, a.a.O., Sūra 26 aš-Šu'ar'à (Die Dichter), Vers 224-226.

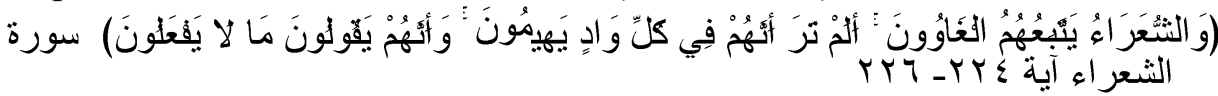

2 Iben Hischam: As sira Anabawiya (Die Sira des Propheten), a.a.O., Bd. 2, S. 300.

$$
\text { ابن هثام: السيرة النبوية، نفس المصدر، ص. . . T؟ }
$$


Stamm selbstverständlich. Dagegen spricht Tralow aber, dass keiner von seinem Stamm an seine neue Religion glaubte; anstatt ihn zu schützen, hatten sie sich gegen ihn gestellt. Nur sein Onkel Abu Talib, sein vorheriger Vormund, erwies sich als treuer Beschützer, obwohl er nicht an ihn glaubte.

Nachdem die Mekkaner oft versucht hatten, Mohammed mit allen Mitteln von seinem Vorhaben abzubringen, wandten sie sich mehrere Male an Mohammeds Onkel, um ihn zu veranlassen, seinen Neffen zum Widerruf seiner Lehre zu bringen und ihn dazu zu bestimmen, dass er seine Angriffe gegen die Götzen aufhöre. Sie wären bereit, alle seine Ansprüche zu erfüllen, wenn es ihm um Macht oder Besitz ginge. Abu Talib versuchte das, aber als Mohammed glaubte, sein Oheim wollte ihm seinen Schutz entziehen, rief Mohammed aus:

„Selbst wenn sie die Sonne in meine rechte und den Mond in meine linke Hand legen, damit ich diese Sache aufgebe, bevor Gott sie zum Siege führt oder ich mit ihr zugrunde gehe, will ich sie nicht aufgeben. Darauf sagte ihm Abu Talib: Gehe nur hin und verkünde, was du willst, ich werde nie meine Hand von dir abziehen. "“l

1 Iben Hischam: As sira Anabawiya (Die Sira des Propheten), a.a.O., Bd. 2, S. 46.

قارن ابن هشام، أبي عبد الملك: السبرة النبوية لابن هشام، نفس المصدر، الجزء الثاني ص.

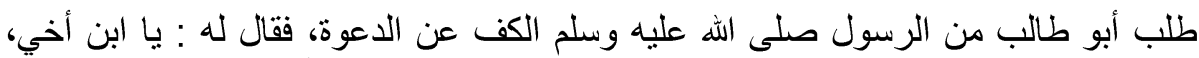

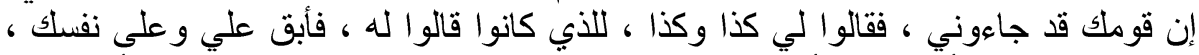

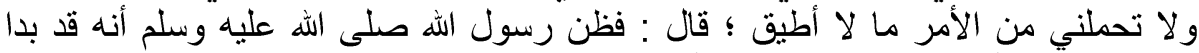

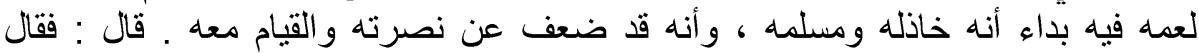

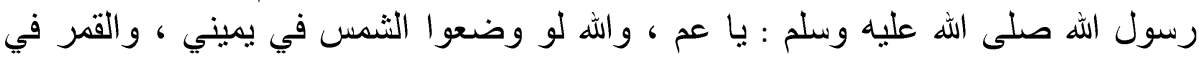

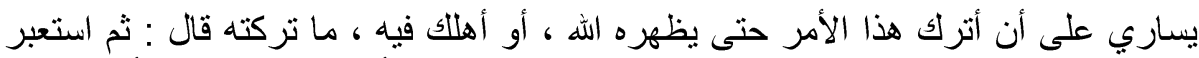

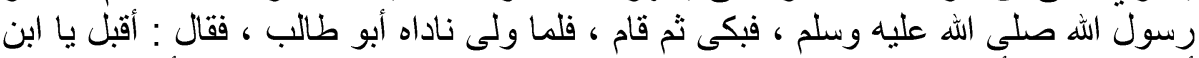

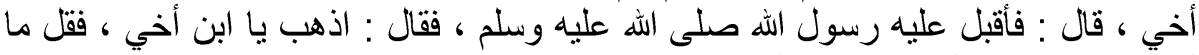
أحبيت ، فو الله لا أسلمك لثيء أبدا. 
Das oben angeführte Beispiel kann als Beweis für Mohammeds Standhaftigkeit gelten. Er beharrte fest auf seinen Glauben, denn er war von seiner göttlichen Sendung überzeugt. Als er diese Antwort an die Mekkaner richtete, war ihm bewusst, dass sie mit der Gefahr verbunden war, sein einziger Beschützer würde ihm seinen Schutz entziehen. Da aber Mohammed als ein unsicherer, wankelmütiger Mensch von Tralow geschildert wird, der nie in der Lage war, solch kritische Situationen zu meistern, wird dieses entscheidende Moment in seinem Leben an anderer Stelle gebracht.

Damit verliert diese Geschichte ihre historische Bedeutung. Im Roman wird diese Geschichte dann geschildert, wo sie zur Darstellung von Mohammeds Resignation dient. Diese Begebenheit soll sich nach den verschiedenen historischen Überlieferungen zugetragen haben, als Mohammed in Mekka noch seine Lehre predigte und bevor er an die Flucht vor den Mekkanern dachte.

Diese Worte, die Mohammed durch seinen Oheim an die Kureischiten richtete, lässt der Autor nicht ganz wegfallen, sondern er bringt sie als Teil eines Gebetes. Dieses Gebet richtet Mohammed in seinem Zufluchtsort Taif an Gott, nachdem er dort enttäuscht und keinen Erfolg gefunden hatte. Er wurde von den führenden Männern in der Stadt zur Flucht gezwungen. Er fand ein Versteck vor ihnen, das ihm ein Sklave besorgt hatte. In diesem Moment soll Mohammed jene Worte an Gott als Bitte zu seiner Rettung ausgesprochen haben. Im Roman heißt es:

„Diese Worte sprach Mohammed in der Stellung des Gebets neben seinem Kamel [...]"“l

In einer solchen Verzweiflung und Demütigung lässt Tralow seinen Helden diese Worte sagen. In dieser Situation

${ }^{1}$ Tralow: Mohammed, a.a.O., S. 148. 
kann Tralow noch einmal den Wankelmut und die Resignation Mohammeds zum Ausdruck bringen.

\section{Die Ausnutzung seiner Anhänger}

Es handelt sich in diesem Beispiel um einen Gläubigen, der einen wohlhabenden jüdischen Mitbürger ermordete, obwohl der Mörder und seine Familie dem Ermordeten zu großem Dank verpflichtet waren. Als der Mord geschehen war und der jüdische Bruder des Mörders ihm heftige Vorhaltungen machte, sagte dieser:

„Auch wenn der, der ihm diesen Mord befohlen habe, ihm geboten hatte, seinen eigenen Bruder umzubringen, hätte er sich nicht bedacht. "

Diese Antwort machte auf den heidnischen Bruder einen gewaltigen Eindruck, er dachte: Eine Religion, die bei ihren Gläubigen einen so unbedingten Gehorsam hervorrufe, muss etwas Sonderbares sein. Darauf bekannte sich auch der heidnische Bruder zum Islam. Durch diesen Fall zeigt Tralow, wie seltsam die Gläubigen an ihrem Propheten hingen und wie Mohammed diesen unbedingten Glauben ausnutzte. Ihm dienten die Gläubigen als Mittel zur Beseitigung seiner Feinde, die Hindernisse in seiner Prophetenlaufbahn bildeten.

Mit den folgenden Worten gibt der Autor seine Meinung über Mohammed unmissverständlich Ausdruck:

„Immer häufiger kam es, dass auf geheimnisvolle Weise Spötter, die sich der Beleidigung des Propheten schuldig gemacht hatten, gewaltsam beseitigt wurden, und dabei erwiesen sich neu angewandte Methoden als besonders wirkungsvoll. Jedenfalls führte die List Mohammed ibn Maslama, für die er ausdrückliche Genehmigung des Propheten eingeholt haben sollte, schließlich zum Ziel. “2

Tralow: Mohammed, a.a.O., 301.

Ebenda, S. 300. 


\section{Die Rücksichtslosigkeit Mohammeds im Fall Nachlas.}

Der Auftrag wurde von Mohammed gegeben; Abdullah (Abdullāh), ein Gläubiger, sollte mit weiteren acht Gläubigen diesen Auftrag durchführen. Abdullah sollte mit seinen Begleitern nach Nachla (Nahla) ${ }^{1}$ ziehen und eine Mekkanische Karawane überfallen. Dies war im gebannten Monat Radschab (Rağab), in dem jede Fehde und jede Gewalttat verboten war. Der Bann wurde von Mohammed verletzt, während er in ganz Arabien respektiert wurde. So wird erstmals die Rücksichtslosigkeit Mohammeds gezeigt und damit begründet, dass Mohammed, wenn es um die Verwirklichung bestimmter Ziele ging, kein Verbot kannte. Es handle auch gegen eigene Verkündigungen, wenn er es für notwendig oder nützlich halte. „Allah liebt die nicht, die Übergriffe begehen “²,

heißt es auch im Koran. Mit diesem Satz werden viele Verse beendet, aber er hat mehr formelle Bedeutung als eine inhaltliche. Weiter wird über diesen Fall berichtet: Als seine Begleiter ihm vorhielten, was Gott sagte, war seine Antwort:

„Vielleicht. Das hängt davon ab, wer gerade stärker ist sie oder wir."3

Als der Einwand erhoben wurde, dass sie in diesem Falle ihre Verwandten angreifen, gab der Führer, der die Zustimmung Mohammeds besaß, als Antwort:

„Nach Verwandtschaft haben die Ungläubigen nicht gefragt, als sie mir meinen Lebensunterhalt versperten. Dreck haben sie mir nachgeworfen! " ${ }^{4}$

Damit wurde der neuen von Mohammed gegründeten Bruderschaft der Stempel der Nützlichkeit für Mohammed

\footnotetext{
Ein Ort liegt zwischen Makka und AṬaif .

Tralow: Mohammed, a.a.O., S. 233.

3 Ebenda,

${ }^{4}$ Ebenda,
} 
aufgedrückt. Angeführt wird als Beweis dafür folgender Fall: Der Führer wurde daran erinnert, dass Stehlen auch eine Sünde ist. Er rechtfertigt sich damit, dass es in Mohammeds Verkündigung davon keine Rede gibt.

Hier beweisen die Gläubigen in der Schilderung Tralows, dass sie Mohammeds Prinzip begriffen, und zwar Offenbarungen für persönliche Ziele auszunutzen. Sie verstanden diese für sich selbst anzuwenden. Und wenn die Begleiter Abdullahs ihm Diebstahl als Sünde vorhielten, so beriefen sie sich auf ihre früheren Traditionen. Aber Stehlen war für die Gläubigen ein legitimes Mittel zum Leben. So derartige Darstellung will Tralow Mohammed offensichtlich unterstellen. Bei dem Überfall wurden einige Mekkaner getötet, andere kamen mit dem Leben davon. Dieser Überfall löste Empörung unter den Gläubigen aus; eine ehrlose Tat, so nannte man dieses Ereignis.

„Es wurde nicht bestritten, dass die Aussendung der Streife rechtlich einwandfrei erfolgt sei. Mohammed hatte Abdullahs Verhalten dann auch nicht offen verurteilen können, sondern lediglich erklärt, dass er von Abdullah und dessen Gefährten missverstanden worden sei. "

Die Empörung war groß und die Täter wurden heftig vom Volke verurteilt. Hier wird der Widerspruch zwischen den Absichten Mohammeds und der Meinung seiner Gläubigen sichtbar. Mohammed meisterte aber diese schwierige Situation, indem er sich auf ein Gebot seines Herrn berief:

„Sie werden dich befragen nach dem Kampf im heiligen Monat. Seinen Frieden zu brechen ist schlimm; aber sich abzuwenden von Allahs Weg, Gott und die heilige Moschee zu verleugnen und sein Volk daraus zu vertreiben ist schlimmer bei Allah; und Verführung

Tralow: Mohammed, a.a.O., S. 241. 
schlimmer als Totschlag. Und sie werden nicht aufhören, euch zu bekämpfen, als bis sie euch von eurem Glauben abtrünnig machen, so sie dies vermögen [...] Aber die, die glauben und die ausgewandert sind und den heiligen Krieg führen, können auf seine Barmherzigkeit hoffen, denn er ist nachsichtig und barmherzig. "

Mit dem Wort Gottes wurden alle Schwierigkeiten beseitigt und diejenigen, die die ehrlosen Taten begangen haben, erhielten die Ehre.

Tralow bringt den Fall von Nachla und zeigt die Offenbarung als ein Mittel der Rechtfertigung des Überfalls. Mohammed hatte zuerst die Beauftragten getadelt, weil sie angeblich seinen Befehl missverstanden hatten. So ist bei Tralow die Offenbarung ein geeignetes Mittel, solche und andere Probleme zu lösen, wenn andere Mittel sich als ungeeignet erwiesen. Tralow drückt das sehr prägnant aus:

\section{„Mit einer Offenbarung ist jeder erledigt. “}

Historiker, wie Haikel, berichten darüber, dass der Gesandte Allahs Abdullah Ibn Dschahsch und eine Gruppe der Muhadschirun im Monat Radschab jenes Hidschra-Jahres zu Nachla sendete. Er übergab ihm ein Schriftstück und befahl ihm, es erst nach zweitägiger Reise zu lesen. Dann sollte er den

1 Ebenda, S. 242, Vgl., As-Șāmit, 'Abdullāh, Frank Bubenheim, Nadeem Elyas: Der edle Qur'ān und die Übersetzung seiner Bedeutungen in die deutsche Sprache, a.a.O., Sūra 2 al-Baqara (Die Kuh), Vers YIV.

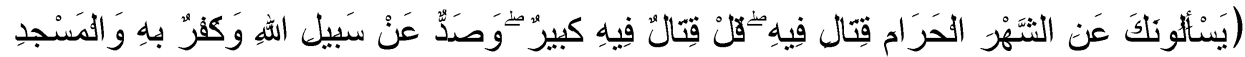

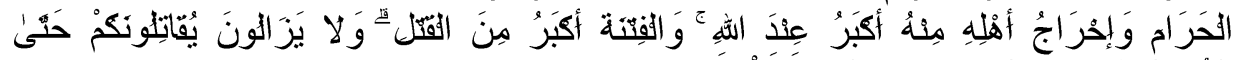

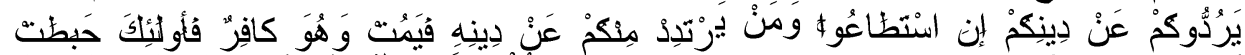

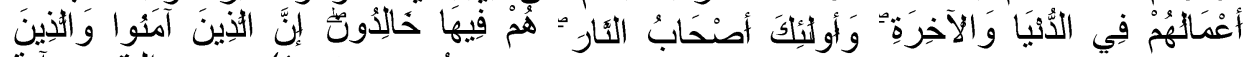

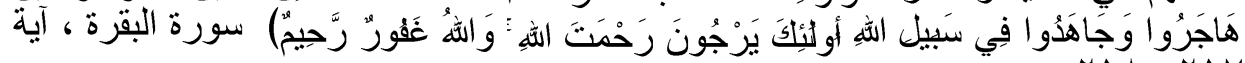

2 Tralow: Mohammed, a.a.O., S. 396. 
im Schriftstück geschrieben Befehl durchführen, ohne irgendjemanden von seinen Gefährten dazu zu zwingen.

Nach zwei Tagen öffnete Abdullah das Schriftstïck, worin stand: „Wenn du dieses mein Schriftstück liest, mach dich auf nach Nachla (zwischen Mekka und AṬaif), beobachte dort Kuraisch und bringe uns das Neueste über sie in Erfahrung." Er unterrichtete seine Gefährten von der Sache und dass er niemanden von ihnen zwinge. Er zog mit seinen Leuten nach Nachla. Dort kam eine Handelskarawane der Kuraisch mit Amr Ibn Al Hadrami an der Spitze an ihnen vorbei. Das war am letzten Tag des Monats Radschab.

Abdullah und die Muhadschirun mit ihm dachten an das, was die Kuraisch ihnen angetan und von ihrem Vermögen an sich genommen hatten, berieten sich und einigten sich zögernd darauf, so viele wie möglich von ihnen zu töten und in Besitz $\mathrm{zu}$ nehmen, was sie bei sich hatten. Einer von ihnen schoss einen Pfeil auf Amr Ibn Al Chadrami ab und tötete ihn; die Muslime nahmen zwei Männer der Kuraisch gefangen.

Nach ihrer Ankunft in Medina ging Abdullah Ibn Dschahsch mit der Karawane und den beiden Gefangenen zum Gesandten. Sie hatten Mohammed bereits ein Fünftel der Beute vorbehalten. Doch als er sie sah, sagte er zu ihnen: „Ich befahl euch nicht, im heiligen Monat zu kämpfen.“ Er setzte die Entscheidung über die Karawane und die beiden Gefangenen aus und weigerte sich, etwas davon anzunehmen. Abdullah und seine Gefährten wurden verlegen, und ihre muslimischen Brüder machten ihnen wegen ihres Tuns heftige Vorwürfe. Die Koraisch nutzten die Gelegenheit aus und begannen zu hetzen, indem sie allerorts verkündeten: „Mohammed (s.a.s.) und seine Gefährten entweihen den heiligen Monat, vergießen in ihm 
Blut, rauben Geld und nehmen Gefangene". So blieb die Lage, bis die vorher erwähnten Verse geoffenbart wurden. ${ }^{1}$

Dadurch ist es klar, dass der Prophet sie nicht befahl, im heiligen Monat zu kämpfen, aber die Koraisch nur $\mathrm{zu}$ beobachten und das Neueste über sie in Erfahrung zu bringen. Als dies geschehen wurde, weigerte sich und nahm nichts davon an. Diese Situation widerlegt die Behauptung Tralows, dass Mohammed die Offenbarung zur Auswirkung seiner persönlichen Ziele und Wünsche ausnutzte.

Historisch war der Zweck der Expeditionstrupps es, die Koraisch einzuschüchtern, ohne sie zu bekämpfen. Mohammed wollte nur durch diese Expeditionstrupps die Koraisch zur Verständigung mit den Muslimen zwingen. Wegen der Verfolgungen der Auswanderer zur koraischiten Karawanen wurde diese Verständigung genötigt, die beide Parteien vor dem Unheil der Feindschaft und des Hasses bewahrte. Sie gewährleistete den Muslimen die Freiheit des Aufrufes zur Religion und den Bewohnern Mekkas die Sicherheit ihres Handels auf ihrem Weg nach Syrien.

Auf anderer Seite verfolgte Mohammed mit diesen Expeditionstrupps und bewaffneten Auszügen ein weiteres Ziel. Vielleicht zielte er auf die Einschüchterung der in Medina und seiner Nähe lebenden Juden, um sich dem Propheten feindselig zu zeigen und auf seine Bekämpfung hinzuarbeiten ${ }^{2}$

Vgl. Haikal: Hayāt Muhammad (Das Leben Muhammads), a.a.O., S. $207 f$.

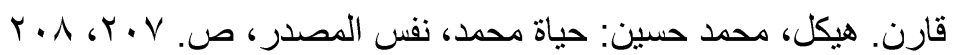

2 Vgl. Haikal: Hayāt Muhammad (Das Leben Muhammads), a.a.O., S. $204 \mathrm{ff}$.

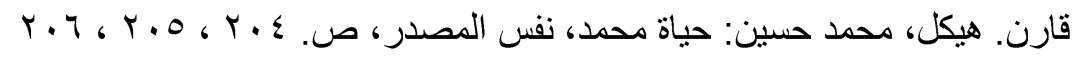


Mohammeds

Neigung

für

kriegerische

Auseinandersetzungen und Vergeltung sowie dessen Vorbereitungen für den Heiligen Krieg

Im Roman war es nun Mohammeds Aufgabe, die Gläubigen gegen ihre Verwandten umzustimmen und auf diese Weise sie für die vorgesehenen Kriege gegen Mekka zu gewinnen.

„Mohammed war Araber genug, um zu verstehen, wie schwierig das Problem war. Wohl wäre es ein Sieg auf der ganzen Linie gewesen, wenn der Vorrang des Bruderschaftsverhältnisses vor der Blutsverwandtschaft durchgekämpft hätte werden können... “l

Es galt für Mohammed also, die religiösen Bindungen den verwandtschaftlichen überzuordnen. Dagegen zeigt der Autor, wie groß die Abneigung der Gläubigen aus Mekka oder aus Medina gegen den Krieg war und besonders gegen eine kriegerische Auseinandersetzung mit Verwandten. Ebenso friedliebend werden die Ungläubigen in Mekka dargestellt, die jeder kriegerischen Verwicklung aus dem Wege gehen wollen. Denn Frieden bedeutete für den Mekkaner Förderung des Handels. Aus diesem Grunde gingen sie, um ihre Handelskarawanen von und nach Mekka zu sichern, Bündnisse mit benachbarten Beduinenstämmen ein.

Als weiterer Grund für Mohammeds Neigung für kriegerische Auseinandersetzungen wird von Tralow die Suche nach Vergeltung angeführt:

„[...] dass Mohammed jahrelang den Versteckten in Mekka von Allah und dem Jüngsten Gericht und von der Vergeltung des Allerhöchsten gepredigt und auch dafür nur Hohn geerntet hatte. “2

Tralow: Mohammed, a.a.O., S. 211.

2 Ebenda, S. 214 
Mit Hilfe der oben angeführten Beispiele versucht Tralow zu zeigen, wie das Ziel Mohammeds mit dem Überfall übereinstimmte, auch wenn er sich anfangs der Masse gegenüber davon distanzierte. Nachdem er die Blutsverwandtschaft durch die Bindung des Glaubens ersetzen konnte, durfte er sein Ziel - die Eroberung Mekkas — nicht aus den Augen verlieren. Dies war auch ein maßgeblicher Grund für die Wallfahrt der Gläubigen nach Mekka. Danach musste jeder Gläubige die Kaaba als heilige Stätte in Mekka wenigstens einmal im Leben besuchen, was auch heute noch seine Gültigkeit besitzt.

In Wirklichkeit wurde diese Pflicht von Mohammed jedoch erst einige Jahre später festgelegt. Denn noch zwei Jahre nach der Auswanderung Mohammeds nach Medina galt Palästina als Gebetsrichtung der Gläubigen. Als die Juden ihn als Propheten nicht anerkennen wollten, bestimmte er -nach Tralow- die Kaaba in Mekka die Gebetsrichtung. Bis dahin galt die Kaaba als Zentrum der Götzen, die Mohammed bekämpfte. So wird die Kaaba das ersehnte Ziel für Mohammed und die Gläubigen und damit wird der Kampf um sie gerechtfertigt. Und auch hier bedient sich Mohammed der Offenbarung Gottes, um jeden Zweifel an der Richtigkeit seines Handelns zu beseitigen.

Mit der Übernahme des folgenden Verses aus Sūre 2 versucht Tralow wieder zu zeigen, wie Mohammed die Offenbarung für seine Ziele benutzt:

„Bekämpft auf dem Wege Gottes die, die euch bekämpfen, aber begeht keine Übergriffe, denn Gott liebt die nicht, die Übergriffe begehen. Tötet sie, wo ihr sie trefft und vertriebt sie von der Stätte, von wo sie euch vertreiben haben, denn Ärgernis ist schlimmer als Mord. Bekämpft sie jedoch nicht beim Heiligtum, es sei denn, dass sie euch dort bekämpfen; und wenn sie euch 
bekämpfen, so tötet sie; denn das ist der Lohn der Leugner. "

Und was Tralow von der Art solcher Offenbarung hält, sagt er im darauffolgenden Satz unmissverständlich:

„Auf diese Weise verkündete Mohammed den heiligen Krieg, den Krieg auf dem Wege Gottes. " ${ }^{2}$

Die Schilderung Tralows stimmt teilweise mit der Überlieferung überein; Mohammed gelang es endlich, die Gläubigen so weit $\mathrm{zu}$ bringen, dass sie sich mit den ungläubigen Mekkanern in eine kriegerische Begegnung einließen. Aus Sure 22, Vers 39, geht hervor, wie Mohammed versuchte, den Kampf gegen die Mekkaner zu rechtfertigen und mit religiösem Inhalt zu versehen.

„[...] Denjenigen, die kämpfen, ist die Erlaubnis gegeben, denn sie haben Unrecht erlitten - und Gott ist Mächtig, ihnen zu helfen. Die aus ihrer Heimat Vertriebenen sind es ohne anderes Recht, als weil sie sagten: Allah ist unser Herr. "*3

Hier wird deutlich, dass Tralow die Quellen zu Mohammeds Leben wohl kannte und studierte, aber bestimmte,

${ }^{1}$ Tralow: Mohammed, a.a.O., S. 214. 215. Vgl. As-Ṣāmit, 'Abdullāh, Frank Bubenheim, Nadeem Elyas: Der edle Qur'ān und die Übersetzung seiner Bedeutungen in die deutsche Sprache, a.a.O., Sūra 2 al-Baqara (Die Kuh), Vers r90, 291.

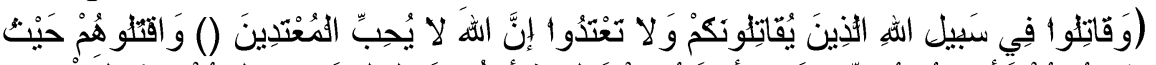

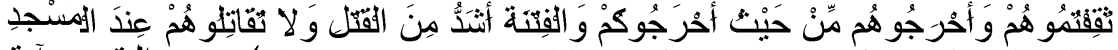

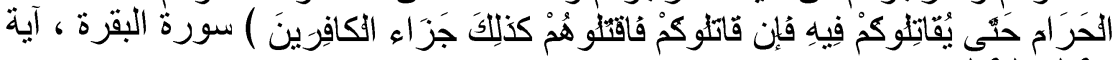

${ }^{2}$ Tralow: Mohammed, a.a.O., S. 215.

${ }^{3}$ Ebenda, S. 214 Vgl., As-Șāmit, 'Abdullāh, Frank Bubenheim u.a.: Der edle Qur'ān und die Übersetzung seiner Bedeutungen in die deutsche Sprache, a.a.O., Sūra 22 al-Ḥağğ (Die Pilgerfahrt), Vers 39, 40.

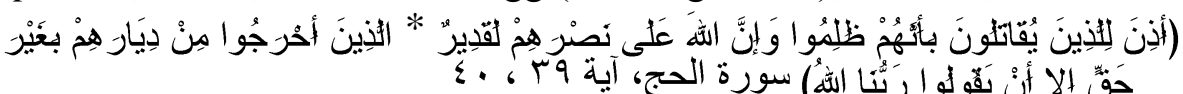


überlieferte Begebenheiten und Vorkommnisse nun Mohammed in seinem Roman anders anordnet. Dies geschieht offensichtlich mit der Absicht heraus, Leben und Werk Mohammeds neu zu gestalten und zu deuten. Dies entspricht jedoch nicht der historischen Darstellung der Überlieferung.

\section{Die Erklärung des Heiligen Krieges oder die Schlacht von} $\underline{\text { Badr }}$

Tralow zeigt die Schlacht von Badr als Mittel zur geplanten Eroberung Mekkas und zur Festigung seiner Macht. Die Schlacht von Badr brach im Roman nach den zunehmenden Überfällen auf Mekkanische Handelskarawanen aus. Diesmal handelt es sich um die große Handelskarawane von Syrien, die auf dem Weg ihrer Rückkehr nach Mekka war.

Mohammed sandte eine entsprechende Anzahl von Männern aus, die die Karawane zu überfallen hatten. Abu Sofian, der Anführer der Karawane, nahm jedoch einen anderen Weg, nachdem er von dem geplanten Überfall erfahren hatte. Er wollte einer Begegnung mit Mohammed aus dem Wege gehen. Abu Sofian gelang es, die Überfallenden irre zu führen und ließ inzwischen seine Leute in Mekka wissen, dass die Karawane in Gefahr sei. Abu Dschahl (Abū Ğaḥl), der sich in Mekka aufhielt, ließ unmittelbar darauf ein großes Heer zusammenstellen mit der Absicht, Mohammed eine Lehre zu erteilen. Durch die Schilderung beider kämpfenden Parteien versucht der Autor einen Überblick über das Geschehen zu vermitteln.

Er überlässt es aber nicht dem Leser, sich ein Urteil über die Kämpfe zu bilden, sondern lässt seine eigene Auffassung deutlich spüren. Die Begeisterung Abu Dschahls und seiner Anhänger für den Krieg sieht Tralow positiv: er führt sie darauf zurück, dass es in diesem Krieg um die Interessen aller Mekkaner gegangen wäre. Die Mekkaner lebten vom Handel, 
und wenn ihre Handelskarawanen von einer Räuberbande angegriffen wurden, mussten sie selbstverständlich um ihr Recht kämpfen. Dieser Meinung waren angeblich - nach Tralows Schilderung- alle Mekkaner. Sie begrüßten Abu Dschahls Enthusiasmus für den Krieg und waren alle bereits, mitzukämpfen. Sie vereinte ein gemeinsames Ziel, nämlich das Volk von den „Räubermördern “ - wie Tralow die Gläubigen nennt $-\mathrm{zu}$ befreien. Im Gegensatz $\mathrm{zu}$ dieser angeblichen Einsicht der Mekkaner in diesem Krieg schildert Tralow die Gegenseite sehr differenziert.

Durch die Gegenüberstellung zwischen den Mekkanern und den Madinern versucht Tralow zu zeigen, wie gerecht der Kampf der Mekkaner und wie ungerecht der Madiner war.

Die Beschreibung der beiden Heere im Roman dient ebenfalls demselben Ziel. Die Mekkaner verfügten über ein stark ausgerüstetes Heer mit tausend Kämpfern aus siebenhundert Kamelen und einhundert Pferden. Mohammeds Heer bestand dagegen aus etwa zweihundert Fußsoldaten, siebzig Kamelen und ein paar Pferden, die bei den Mekkanern gestohlen worden waren.

Mohammed hatte keine andere Wahl, dem zahlenmäßig überlegenen Heer der Mekkaner gegenüberzustehen. In ihm verstärkte sich nun der Hass gegen die Ungläubigen, die ihm und seinen Gott verhöhnt hatten. Es war also Allahs Kampf, der heilige Kampf, wie Tralow ihn darstellt. Dann verkündete Mohammed seinen Kämpfern, dass jeder im Kampf auf dem Wege Gottes Gefallene sofort das Paradies erlange.

„Ohne Fegefeuer! Ohne Jüngstes Gericht! Alle Sünden seien gebüßt und durch Allahs Barmherzigkeit verziehen! "

Tralow: Mohammed, a.a.O., S. 268. 
Damit wird noch einmal gezeigt, wie Mohammed seine Verkündigung für eigene Zwecke benutzt. Das Jüngste Gericht war ein Mittel für Mohammed, seine Lehre durch Drohung mit ihm zu verbreiten. Da ihm jetzt dieses Gericht als Hindernis im Kampf erscheint, kann es auch ausscheiden. Auf diese Weise zeigt der Roman, wie Mohammed die Kampfeslust unter seinen Gläubigen mit Hilfe solcher Aussagen weckte: einmal mit Hilfe des versprochenen Paradieses, zum anderen mit der Beute.

So klug und bedacht wird Mohammeds Geschicklichkeit dargestellt. Er wusste, dass eine Niederlage in diesem Kampf den Untergang für seine Zukunft bedeutet.

Tralow ergreift für die Mekkaner Partei. So wird der Kampf der Mekkaner um die Rettung ihrer Handelskarawane als gerecht bewertet, da viele der Mekkaner an diesen Karawanen beteiligt waren. Aber nachdem die Karawane bereits durch Abu Sofian in Sicherheit gebracht worden war, änderte sich die Haltung der Mekkaner, sie wurden aus Verteidigern zu Angreifern. Ihr Ziel war es, Mohammed und seine Gläubigen $\mathrm{zu}$ vernichten. Das wird von Tralow gerechtfertigt. Als ein Mekkaner meinte, die Karawane sei doch gerettet und der Kampf nicht mehr notwendig, antwortete Abu Dschahl:

„Allerdings nicht [...] Aber Mekka? Ohne seinen Handel ist Mekka nicht lebensfähig. Auf unseren Felsbrocken wächst nichts [... ${ }^{\text {“" }}$

Der einzige Grund für den Kampf der Gläubigen war nach Tralows Darstellung nur die versprochene Beute, sei es im Jenseits oder im Diesseits. Der Glaube an das Paradies und der

Tralow: Mohammed, a.a.O., S. 262 
blinde Gehorsam der Gläubigen waren auch die Ursache für ihren Sieg in diesem Kampf.

Währenddessen versucht der Autor, den Leser für die Stellungnahme der Mekkaner zu gewinnen. In diesem Zusammenhang sucht Tralow einen Grund für ihre Niederlage zu finden. Er stellt die Mekkaner als Handelsleute dar und nicht als Krieger. Die Mekkanischen Handelskarawanen wären nie in Gefahr gewesen, wenn sie nicht von Mohammeds Gläubigen angegriffen worden wären. Der Frieden in und um Mekka sei also erst durch Mohammed gestört worden. Sonst brauchten sie nicht die Waffe zu gebrauchen. Außerdem seien es die Mekkaner gar nicht gewöhnt gewesen, solche kämpferische Auseinandersetzung zu führen.

Tralow zeigt deutlich sein Bedauern über die Niederlage der Mekkaner, und versucht sie aber gleichzeitig zu rechtfertigen. Die Gläubigen waren nach seiner Schilderung im Vorteil dadurch, dass die meisten von ihnen Fußsoldaten waren, während die Mekkaner fast alle Beritten gewesen sind. Tralow berichtet:

„Der Vorteil der Krieger zu Fuß bestand nun darin, dass immer mehrere von ihnen sich mit einem Angreifer befassen konnten, dass die Beinsehnen der Tiefe vom Boden aus unschwer durchzuhauen waren und ein abgeworfener, am Boden liegender Reiter mit Leichtigkeit abzutun war. "

So drückt sich Sympathie Tralows für die Mekkaner aus. Den Ausgang des Kampfes fand Tralow nicht gerecht. Denn er hielt den Kampf der Mekkaner als einen Kampf für eine gerechte Sache. Er sieht die Interessen der Patrizier als gemeinsames Interesse der Masse an. Sie kämpften im Roman gegen eine Schar von Raubmördern. Der Kampf der Gläubigen

\footnotetext{
${ }^{1}$ Tralow: Mohammed, a.a.O., S. 270.
} 
dagegen diente nur der Verwirklichung einiger Ziele, die nach wie vor im Interesse eines ehrgeizigen Schwärmers lagen.

Im Roman nahm Mohammed selbst an der Schlacht nicht teil, sondern schlich sich in eine Hütte mit der Behauptung, er erwarte eine Offenbarung, wodurch er sich der Schlacht entziehen konnte. Indem Tralow das Kampfziel der Mekkaner als gerecht bewertet und ihre Niederlage bedauert, kritisiert er Mohammed und seine Anhänger.

Eine solche Bewertung der Gestalt Mohammeds ergibt sich offenbar auch aus dem Einfluss der europäischen Orientalisten auf Tralow.

Es ist bemerkenswert, dass Tralow seinen Helden Mohammed als einen normalen Menschen und nicht als einen Propheten darstellt. Zugleich vergisst Tralow, dass der Prophet sich in seinem Tun und Lassen auf die Offenbarung bezieht.

\section{Das gebilligte Gelöbnis und das Abkommen von Al} Hudaibija

Im Roman wird berichtet, dass Mohammed seinen Schwiegersohn 'Osman nach Mekka geschickt hatte, um dort Friedensverhandlungen vorzuschlagen. Dann heißt es aber unmittelbar daraufhin:

„[...] Und dann versammelte er seine Anhänger unter einem grünen Baum und ließ sie schwören, ihn in dem bevorstehenden Entscheidungskampf nicht im Stich zu lassen. Mit Begeisterung legten die Gläubigen den Eid $a b$, obwohl nach menschlichem Ermessen der Kampf einer verhältnismäßig so kleinen Schar nur halbbewaffneter Männer gegen eine große Übermacht völlig hoffnungslos war. "“l

Tralow: Mohammed, a.a.O., S. 345. 
Wenn diese Stelle im Roman mit der historischen Überlieferung verglichen wird, kann eine Veränderung erkannt werden, die Tralow mit einer bestimmten Absicht vorgenommen hat. Im Roman wird kein Grund angegeben, weshalb Mohammed seine Anhänger um sich versammelte und sie auf den bevorstehenden Kampf vorbereitete. Der Kampf fand nicht statt, weil es keinen Grund mehr dafür gab.

Wenn man jedoch in der Überlieferung nach dem Grund sucht, für den Mohammed seine Anhänger um sich versammelte, kann es kein Zweifel daran bestehen, dass es in der Versammlung um 'Osman und seine Begleiter ging. Es hatte sich das Gerücht verbreitet, dass sie von den Mekkanern ermordet worden waren. Dieses Gerücht wurde noch dadurch gekräftigt, dass man drei Tage lang keine Nachricht erhielt.

Der Prophet mutmaßte, dass Kuraisch 'Osman ermordet und Verrat im heiligen Monat begangen haben. Deshalb sagte er: „,Wir ziehen nicht ab, ehe wir gegen die Leute gekämpft haben. "1 Er rief seine Gefährten zu sich unter einen Baum in diesem Tal, und sie gelobten ihm alle Treue, dass sie bis zum Tod nicht fliehen würden. Sie gelobten ihm Treue für die Vergeltung an den Verrätern und Mördern. Sie gaben ihm das gebilligte Gelöbnis $\mathrm{ab}$, zu dem die Worte des Erhabenen geoffenbart wurden:

„Allah hatte ja Wohlgefallen an den Gläubigen, als sie dir unter dem Baum den Treueid leisteten. Er wusste, was in ihren Herzen war, und da sandte Er die innere Ruhe auf sie herab und belohnte sie mit einem nahen Sieg ${ }^{2}$

${ }^{1}$ Haikal: Hayāt Muhammad (Das Leben Muhammads), a.a.O., S. 299, 300 .

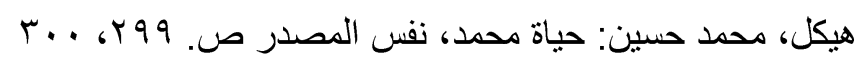

2 As-Șāmit, 'Abdullāh, Frank Bubenheim, Nadeem Elyas: Der edle Qur'ān und die Übersetzung seiner Bedeutungen in die deutsche Sprache, a.a.O., Sūra 48 al-Fatḥ (Der Sieg), Verse, S 18. 
Dieser Zwischenfall wird im Roman nicht erwähnt, mit der Absicht, Mohammeds Zuneigung zum Krieg zu betonen, die keine Begründung für eine Kriegserklärung braucht. Tralow stellt hier Eigenschaften Mohammeds, die er schon in anderen Situationen gezeigt hatte, diesmal unter einem anderen Gesichtspunkt wieder dar.

Diese Eigenschaften zeigen sich sehr deutlich in Mohammeds Vorhaben, mit seiner kleinen Schar nur unzureichend bewaffneter Männer gegen eine Mekkanische Übermacht kämpfen zu wollen. Durch Verhandlungen kamen schließlich beide Seiten zur Einigung über einen Friedensvertrag für die Dauer von zehn Jahren.

Diese Einigung mit den Mekkanern konnte nur die friedliche Absicht Mohammeds bestätigen. Denn wenn Mohammed einen Krieg gewollt hätte, hätte er seine Anhänger besser mit Waffen ausgerüstet. Die Schlacht bei Badr weist außerdem darauf hin, dass Mohammed nicht gescheut hätte, mit einer geringen Anzahl von Kriegern gegen eine Übermacht anzukämpfen. Die geringe Anzahl hindert ihn nicht daran, wenn er eine kriegerische Auseinandersetzung beabsichtigt hätte.

Tralow versucht dagegen die Lage Mohammeds wie folgt $\mathrm{zu}$ zeigen:

„Sein Ziel war, so bald wie möglich die Wiederzulassung der Gläubigen zur Kaaba zu erzwingen. "l

Wenn dies die eigentliche Absicht Mohammeds gewesen wäre, hätte er doch nicht mit den Mekkanern auf Verhandlungen einzugehen gebraucht. Mohammed war nur mit

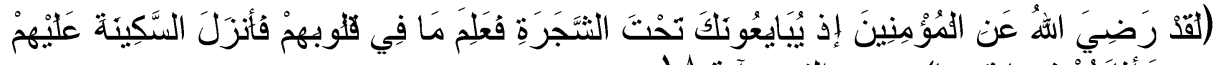

1 Tralow: Mohammed, a.a.O., S. 347. 
den notwendigsten Waffen zur Selbstverteidigung im Notfall ausgerüstet.

Dagegen waren es die Mekkaner. Sie wollten anfangs auf keine Verhandlung eingehen und Mohammed mit Gewaltanwendung von seinem Vorhaben zur Durchführung der Pilgerschaft abbringen. Die Mekkaner, die dies wollten, gehörten der aristokratischen Oberschicht an. Sie waren Wucherer, Sklavenhalter und Großhändler. Letztlich setzte sich aber die Friedenspartei durch, die auch aus Vertretern dieser Oberschicht bestand.

Aus dem Vertrag geht auch hervor, dass Mohammed Mekka zur Pilgerschaft zusammen mit seinen Gläubigen für drei Tage im Jahr besuchen durfte. Diese Pilgerschaft wurde von den Gläubigen ungestört vollzogen. Aber bei diesem Besuch in Mekka wird Mohammed von Tralow die Absicht zugeschrieben, den beschlossenen Friedensvertrag verletzen zu wollen. Tralow fügt an dieser Stelle eine Episode an, mit der er diese Absicht Mohammeds verdeutlichen will. Als einer der Gläubigen Mohammed an den Vertrag, den Mohammed angeblich nicht beachten wollte, erinnerte und meinte, sie sollen Mekka laut Vertrag verlassen, hatte Mohammed gesagt:

„Ach was, Vertrag! Als wenn es etwas ausmachte." „Sehr viel! Versetze dich doch in Suhails [...]". Mohammed sagte darauf: „Bedenke doch, welche Möglichkeiten das für uns ergäbe! "“l

Dies ereignet sich, als Mohammed gerade dabei war, eine weitere Frau heiraten und den Hochzeitstag festlegen zu wollen. Dies zeigt Tralow als einen ausreichenden Grund für Mohammed, seinen Aufenthalt in Mekka zu verlängern, ohne den Vertrag zu beachten. Aber als er Mekka verlassen musste, ließ er die bereits vereinbarte Ehe fallen:

Tralow: Mohammed, a.a.O., S. 391. 
„Heiraten muss ich nun allerdings anderswo "1

Hier zeigt sich, dass Tralow bei der Darstellung des Lebens und Wirkens von Mohammed keinen Unterschied mache zwischen der Gestaltung der privaten Sphäre und Mohammeds Tätigkeit als Politiker und Staatsmann.

\section{Die Eroberung Mekkas zur Stabilisierung der Macht} Mohammeds

Tralow kommt seine Stellungnahme zur Eroberung Mekkas zum Ausdruck. So schildert er den Überfall des Stammes Kinana, der mit den Mekkanern verbündet war, auf den Stamm Chuzaa als kein ausreichender Grund für die Eroberung Mekkas. Der letztere stand mit Mohammed im Bündnis. Die Verbündeten der Mekkaner benutzten in ihrem Überfall Mekkanische Waffen. Da der Friedensbruch eindeutig von Seiten der Mekkaner begangen wurde, versucht Tralow diesen Umstand zu mildern. Er meint, dass das kein ausreichender Grund gewesen wäre, die Mekkaner deshalb zur Rechenschaft zu ziehen. Da Mohammed aber, Tralows Meinung nach, nur auf die Andeutung eines Grundes wartete, um gegen die Mekkaner kämpfen zu können, kam ihm dieser Umstand recht.

In der Überlieferung wird berichtet, dass die Mekkaner die sich bietende Gelegenheit ausnutzen wollten, um Mohammeds Macht zu brechen. Mohammeds Heer, das er nach Ostjordanien sandte, wurde eine große Niederlage zugefügt. Danach hatten die Mekkaner ihren verbündeten Stamm angestiftet, Mohammeds Verbündete wiederum zu überfallen. Abu Sofian und andere Männer der Friedenspartei versuchten aber, einer möglichen Rache für den Überfall von Seiten Mohammeds vorzubeugen und damit einen kommenden Krieg zu verhindern.

Tralow: Mohammed, a.a.O., S. 392. 
Nach dem Überfall ging Abu Sofian zu Mohammed und versuchte, den Konflikt auf friedlichem Wege zu lösen. Seine Bemühungen waren jedoch völlig erfolglos. Mohammed ließ schnell ein großes Heer ausrüsten, um den Mekkanern zuvorkommen zu können und sie dadurch zur kampflosen Kapitulation zu bringen. Und so geschah es auch. ${ }^{1}$

In der Überlieferung zeigt sich eine subjektive Schilderung aus der Sicht Mohammeds, die auf diese Weise den Feldzug Mohammeds gegen Mekka in sein Gegenteil verkehrt und ihm friedlichen Charakter zuschreibt. Tralow verfällt jedoch bei der Schilderung dieses Überfalls in das andere Extrem:

Mohammed lehnte alle Friedensvorschläge ab, weil er es endlich an der Zeit fand, Mekka zu erobern. Abu Bakr, der Schwiegervater Mohammeds und gleichzeitig sein Berater, schlug ihm vor:

\section{„Mit etwas Geschicklichkeit wird man Mekka dazu bringen, dass es die Kinana zum Frieden mit Chuzaa veranlasst. "2}

Mohammed drehte ihm die Worte im Munde um, da er nach Tralows Schilderung nur die Sprache des Krieges verstand; er fragte Abu Bakr:

„Du bist also auch der Meinung, dass Mekka den Waffenstillstandsvertrag gebrochen hat ${ }^{\text {(3) }}$

Abu Bakr erschrak,

„Das habe ich nie sagen wollen. "4

${ }^{1}$ Haikal: Hayāt Muhammad (Das Leben Muhammads), a.a.O., S. 330f. هيكل، محمد حسين: حياة محمد، نفس المصدر ص. ST

2 Tralow: Mohammed, a.a.O., S. 400.

3 Ebenda, S. 401.

4 Ebenda, 
Mohammed handelte auch gegen den Rat seiner Gefährten, wenn sie den Frieden wollten und er nicht mit ihnen übereinstimmte. Er beurteilte Dinge nur nach ihrer Nützlichkeit für ihn und seine Ziele. Wie Tralow es darstellt, wird auch Gottes Wille dazu von Mohammed in Anspruch genommen. Gott soll es gewesen sein, der zum Friedensbruch führte:

„Darum sandte er uns den Bruch des Waffenstillstandes durch Mekka. Weil wir dadurch das Recht auf die Eroberung Mekkas bekommen, tat er das. "'l

So hebt Tralow die Absicht seines Helden hervor, nämlich Mekkas Eroberung und stellt sie als das lang ersehnte Ziel Mohammeds dar.

Aus der Schilderung des Lebens in Mekka geht hervor, dass Tralow bemüht ist, zu zeigen, dass Mohammed mit seinem Auftreten nicht nur überflüssig war, sondern dass er sogar Mekka noch Unheil gebracht hatte.

\section{Erzählperspektive}

Johannes Tralow verwendet zur Darbietung der Vorgänge in seinem Roman Er-Erzähler, der alle Einzelheiten vermittelt und kommentiert. Als Beispiel dafür wird in der achten Seite ausgeführt:

„Während man sich so mit Lachen und Geschwätz in der

Küche tummelte, hätte es leicht geschehen können, dass alle diese Vorbereitungen in ihrem ganzen Umfang gar nicht mehr nötig gewesen wären. “2

Die Erzählperspektive ist überwiegend auktorial. Die subjektiven Züge dieses auktorialen Erzählers werden eliminiert. Somit hat der Roman Tralows „Mohammed“ den Anschein einer wissenschaftlichen Arbeit, lediglich auf Beschreibung und Berichterstattung beruhend.

\footnotetext{
${ }^{1}$ Tralow: Mohammed, a.a.O., S. 401.

${ }^{2}$ Ebenda,
} 
Der Erzähler hebt seine Erzählerrolle hervor. Die Berichterstattung in Tralows Roman „Mohammed“ erscheint dem Leser zunächst neutral.

„Das war immer so gewesen, und niemanden hatte es angefochten, auch den Mann nicht ". ${ }^{1}$

Aber in der auktorialen Erzählperspektive zeichnet sich die Einstellung des Autors $\mathrm{zu}$ politischen, sozialen und moralischen Fragen, seine Voreingenommenheit gegenüber bestimmten Personen und Dingen ab. Der Autor gibt seinen subjektiven Standpunkt durch den auktorialen Erzähler:

„Man konnte Mohammed ohne Übertreibung als den politischen Herren Arabiens bezeichnen ". ${ }^{2}$

Hier gibt sich der auktoriale Erzähler als solcher zu erkennen, Tralow gibt seine Stellungnahme ab, sollte die Erzählung stellenweise zu subjektiv sein.

Was die Ironie betrifft, sieht Tralow seinen Helden auch nicht unkritisch. Es kann von einer partiellen epischen Ironisierung gesprochen werden, die eine historische Distanz in aller erzählerischer Unmittelbarkeit herstellt. Solche ironischen Züge durchziehen den ganzen Komplex von Mohammeds Verhältnis zur Poesie. Allerdings macht Tralow auch die tiefere Problematik deutlich. Hinweise auf dieses Verhältnis durchziehen wiederum das ganze Buch.

„Mohammed Ibn Abdallah war kein Märchenerzähler. Er würde sich eine solche Behauptung sehr verbeten haben, und mit der gleichen Empfindlichkeit stand er Wahrsagern und Dichtern, vor allem den Dichtern, gegenüber, die er hasste. Er hätte sich überhaupt alles verbeten zu sein, außer was er war, nämlich Mohammed

\footnotetext{
${ }^{1}$ Tralow: Mohammed, a.a.O., S. 7.

${ }^{2}$ Ebenda, S. 414.
} 
ibn Abdallah, der Haschimit und Allahs Prophet. Statt seine Offenbarungen als Ausstrahlung seines eigenen Geistes zu erkennen, verehrte er sie als Botschaften göttlichen Ursprungs. “l

Mohammed muss einmal einem Märchenerzähler weichen, weil er selber mit der Möglichkeit der Bekehrung eines weitgereisten Mannes rechnen konnte. Den Märchenerzähler hasste er von nun an,

„Weil er seit dieser Nacht glaubte, der Künstlerberuf des anderen sein eigenes Prophetenansehen in den Schatten. " ${ }^{2}$

Und Tralow, der ausgerechnet das ganze Märchen wiedergibt, kommt noch einmal auf Mohammeds Hass zurück:

„Durch den Gedanken [...], dass er der Kunst eines der von ihm so verachteten Dichter hatte weichen müssen, fühlte sich der Mann der Offenbarung aufs Tiefste verletzt, empfang er alles, was ihm unwiderlegliches religiöses Wissen war, als schändlich befleckt ${ }^{\text {"3 }}$

Nach Tralow konnte der an Misserfolg gewohnte Prophet ganz zuletzt die Niederlage durch einen Poeten nicht ertragen. Die Gefahr liegt darin, dass seine Offenbarungen als Ausstrahlungen seines eigenen Geistes genommen wurden, wie die Märchen, wie die Poesie, und das war für Mohammed zu groß.

\section{Zusammenfassung und Schlussfolgerungen der Arbeit}

Insgesamt vermittelt der Roman viele aufschlussreiche Fakten über Haltungen, Ansichten und Gebräuche der Araber zur Zeit Mohammeds. Tralow berichtet über die

\footnotetext{
${ }^{1}$ Tralow: Mohammed, a.a.O., S. 88.

2 Ebenda, S. 107.

3 Ebenda, S. 122.
} 
Voraussetzungen, die zur Entstehung des Islams führten, und über dessen Entwicklung und Weiterverbreitung. Tralow richtete auf Mohammeds Ausnutzung der göttlichen Offenbarungen in den verschiedenen Situationen besonderes Augenmerk.

Tralow will in seinem Roman zeigen, dass die rasche Ausbreitung der Religion Mohammeds nicht auf das Wirken eines Gottes, sondern auf eine vorteilhafte Konstellation ökonomischer und politischer Fakten zurückzuführen ist.

In diesem Zusammenhang steht das Bild des Propheten Mohammed. Tralow will diese Figur vor einen konkrethistorischen Hintergrund, frei von mythischen Vorstellungen und Ausschmückungen darstellen, die im Laufe von Jahrhunderten um sie entstanden sind. Er selbst aber verändert auch die historische Überlieferung, um Mohammed so zu zeigen, wie er ihn sehen will.

Tralow lässt die Charaktereigenschaften seines Helden sehr deutlich zum Ausdruck kommen, indem er ihn in Entscheidungssituation stellt. Tralow wollte hier erweisen, dass es Mohammed in erster Linie um die Durchsetzung persönlicher Interessen und Ziele geht.

Dadurch wird es klar, dass Tralow die Ereignisse und Begebenheiten, die der Prophet mit der Offenbarung beendete, oder die mit der Biographie des Propheten verbunden sind, missverstand. Er sieht Mohammed als einen normalen Menschen und nicht als Propheten an, der seine Ziele und Wünsche mit irgendeinem Mittel durchführen will. Das ist jedoch nicht richtig, weil der Prophet sich immer auf die Offenbarung alles stuitzt, was er tun und aussagen kann. Diese Wahrheit bekräftigt der Koran: 
„Und er redet nicht aus (eigener) Neigung. Es ist nur eine Offenbarung, die eingegeben wird. "l

Tralow wollte einen Roman für den an der Historie interessierten Leser schreiben und ihm ein objektives und kritisches Bild von Mohammeds Leben und Gestalt vermitteln. Dies erfüllt sich jedoch nicht, weil Tralow sich nicht dazu verpflichtet, was er früher aussagte, Mohammed von den Zudichtungen und Legenden, die um ihn im Laufe der Zeit entstanden, zu befreien

Aus der historisch unumstrittenen Bedeutung Mohammeds ist es erklärlich, dass diese Gestalt sehr oft Gegenstand der Dichtung in der Weltliteratur wurde. Aus der unterschiedlichen Stellung der Dichter ergeben sich unterschiedliche Auffassungen von der Bedeutung und der Größe Mohammeds.

\section{Literaturverzeichnis \\ Deutsche Primär- und Sekundärliteratur:}

- Abu-Hattab, Mohammed: Zum Bild des Propheten Mohammed in Bezug auf seine Darstellung in Europa. Betrachtungen eines arabischen Germanisten. In: Wissenschaftliche Zeitschrift der Fremdsprachenfakultät an der Al-Azhar Universität, 6/1982..

- Buhl, Frants: Das Leben Mohammeds, aus dem Dänischen übersetzt von H.H. Schaeder. Leipzig 1930.

- Mohammed ibn Ischak, „Das Leben Mohammeds“, bearbeitet von Abd el-Malik ibn Hischam. A.d. Hss. Hsrg. Von Ferdinand Wüstenfeld Bd. I-II. Göttingen $1858-1860$

\footnotetext{
${ }^{1}$ As-Ṣāmit, 'Abdullāh, Frank Bubenheim, Nadeem Elyas: Der edle Qur'ān und die Übersetzung seiner Bedeutungen in die deutsche Sprache, a.a.O., Sūra 53 an-Nağm (Der Stern), Vers 3, 4.

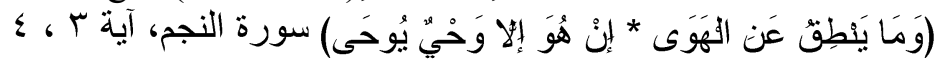


- Rashid, Adnan: Die literarische Darstellung des Propheten Mohammed in der deutschen Literatur unter Berücksichtigung des Zeitraumes von 1917 bis 1967.

- R G H: Johannes Tralow, ein Meister des historischen Romans, In: Mittelungen der Deutsch-Türkischen Gesellschaft, Bonn 76/1967.

- Penzhold, Leonhard: Tralow-Ausstellung der Deutschen Staatsbibliothek, In: Der Bibliothekar, Leipzig 21/1967.

- Sprenger, Aloys: Das Leben Mohammeds, aus Dänischen übersetzt von H.H. Schaeder. Leipzig 1930.

- Tralow, Johannes: Mohammed, 3. Auflage 1990, Verlag der Nation Berlin 1967.

- Tralow, Johannes: Leben und Werk. Hg. Deutsche Staatsbibliothek, Berlin. 1968.

\section{المراجع العربية}

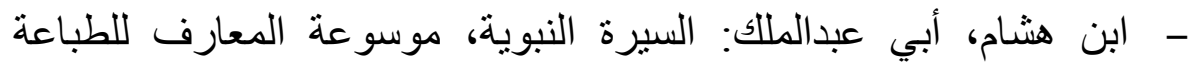

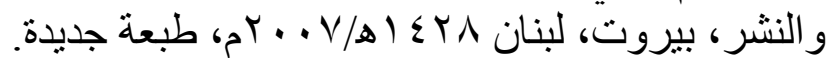

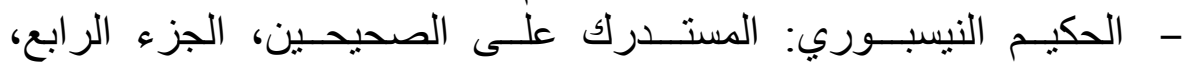

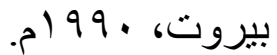

- الخضــيري، محمد عفيفي: نور اليقين في سـيرة سيـد المرســين ، دار

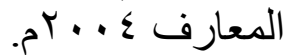

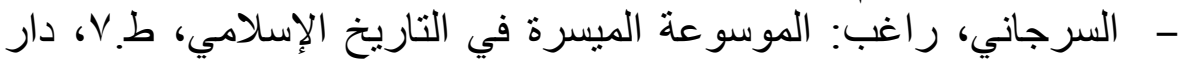

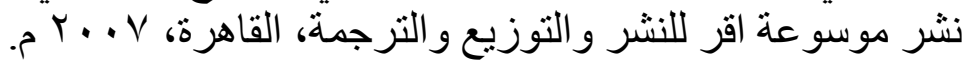

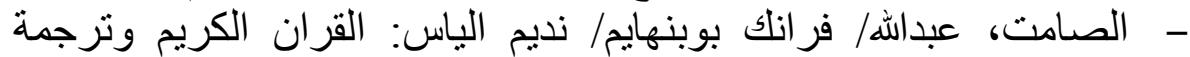
معانيه إلى اللغة الألمانية، مجمع الملك فهد لطباعة القيامة القرآن الكريم، المملكة

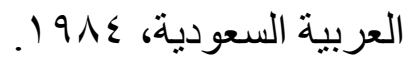
- - هارون، عبدالسلام: تهذيب سيرة ابن هينة هئام، دار إحياء التراث العربي،

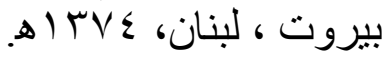

